\title{
Animation: can it facilitate?
}

\author{
Barbara Tversky and Julie Bauer Morrison ${ }^{\dagger}$ \\ Department of Psychology, Jordan Hall; Bldg. \#420 Stanford, CA 94305-2130 USA. \\ email: bt\{julie\}@psych.stanford.edu.
}

\section{Mireille Betrancourt}

I.N.R.I.A. Rhone-Alpes, 655, Av. de l'Europe, 38330 Montbonnot St-Martin, France. email: mireille.betrancourt@inria.fr.

\section{(Received 1 March 2001 and accepted in revised form 4 April 2002)}

\begin{abstract}
Graphics have been used since ancient times to portray things that are inherently spatiovisual, like maps and building plans. More recently, graphics have been used to Portray things that are metaphorically spatiovisual, like graphs and organizational charts. The assumption is that graphics can facilitate comprehension, learning, memory, communication and inference. Assumptions aside, research on static graphics has shown that only carefully designed and appropriate graphics prove to be beneficial for conveying complex systems. Effective graphics conform to the Congruence Principle according to which the content and format of the graphic should correspond to the content and format of the concepts to be conveyed. From this, it follows that animated graphics should be effective in portraying change over time. Yet the research on the efficacy of animated over static graphics is not encouraging. In cases where animated graphics seem superior to static ones, scrutiny reveals lack of equivalence between animated and static graphics in content or procedures; the animated graphics convey more information or involve interactivity. Animations of events may be ineffective because animations violate the second principle of good graphics, the Apprehension Principle, according to which graphics should be accurately perceived and appropriately conceived. Animations are often too complex or too fast to be accurately perceived. Moreover, many continuous events are conceived of as sequences of discrete steps. Judicious use of interactivity may overcome both these disadvantages. Animations may be more effective than comparable static graphics in situations other than conveying complex systems, for example, for real time reorientations in time and space.
\end{abstract}

(C) 2002 Elsevier Science Ltd. All rights reserved.

\section{Graphics: The Congruence Principle}

\subsection{SOME FUNCTIONS OF GRAPHICS}

The enthusiasm for graphics of all kinds rests on the belief that they benefit comprehension and learning, and foster insight (their proponents include Levie \& Lentz, 1982; Larkin \& Simon, 1987; Winn, 1987, 1989; Levin \& Mayer, 1993; Schnotz

\footnotetext{
${ }^{\dagger}$ Julie Bauer Morrison is now at Bryant College, Smithfield, RI.
} 
\& Kulhavy, 1994; Tversky, 1995, 2001; Scaife \& Rogers, 1996). Many advantages of graphics have been proposed. Graphics provide an additional way of representing information; two codes, pictorial and verbal, are better than one. Graphics may be aesthetically appealing or humorous, attracting attention and maintaining motivation. Graphics, as the saying goes, may save words by showing things that would otherwise need many words to describe. This especially holds for faces, maps, systems, and the like that are naturally spatial and hard to describe or visualize. Since shepherds first notched sticks to keep track of their flocks or hunters bent trees to remember a route, graphics have been used to record information, historical, political, economic and personal. Such records have appeared in myriad forms, including tallies, notches and tokens (e.g. Gelb, 1963; Schmandt-Besserat, 1992). Analysis of these graphics, ancient and modern, reveals common uses of space and the things in it to convey other concepts (Tversky, 1995, 2001). Graphics use visual elements and the spatial relations among them to represent elements and relations that may be visuospatial, or may be metaphorically visuospatial, applying the power of spatial inference to other domains (Larkin \& Simon, 1987; Tversky, 1995, 2001). Thus, another function of graphic displays is to use space to organize information and to facilitate memory and inference. Computer menus are a familiar modern example, but using space to organize and remember is also an ancient practice (e.g. Bower, 1970; Small, 1997; Yates, 1969). Graphics externalize internal knowledge. This has at least two benefits. The benefit to the individual mind is reducing the burden on memory and processing by off-loading. The benefit to groups of minds is joint consideration of the same set of ideas as well as collective revision of them. Finally, graphics have been used to promote inference and discovery by making the underlying structures and processes transparent (e.g. Dwyer, 1978; Larkin \& Simon, 1987; Mayer, 1989; Bauer \& Johnson-Laird, 1993; Tessler, Iwasaki \& Kincho Law, 1995). Interestingly, for these purposes, simple graphics with less detail are often more effective than more realistic ones (e.g. Dwyer, 1978), provided that they abstract the essential conceptual information.

\subsection{VISUALIZATIONS OF THE VISIBLE AND OF THE ABSTRACT}

Graphic displays can be loosely divided into two kinds: those that portray things that are essentially visuospatial, like maps, molecules and architectural drawings, and those that represent things that are not inherently visual, like organization charts, flow diagrams, and graphs. Graphics that portray essentially visual or spatial information have a clear and obvious advantage over other means of conveying that same information, notably language, in that they use space to convey space. This natural correspondence does not mean that all space to space graphics are immediately understood. Certain aspects of maps are difficult for children (De Loach Miller \& Rosengren, 1997; Liben, 1999) and even adults, especially three-dimensional depictions (e.g. Gobert, 1999; Fontaine, 2001). In spite of the natural correspondences mapping space to space, there are situations where clear language is as effective as graphics (e.g. Taylor \& Tversky, 1992). Graphics that portray things that are not inherently visuospatial rely on spatial metaphors. Pictorial elements can represent abstract meanings through "figures of depiction", for example, metonymy, where a concrete associate represents an abstract concept, such as the White House for the presidency or 
a pair of scissors for "delete". Spatial proximity is the basic metaphor underlying using space to express abstract relations. Distance in space conveys distance on some abstract dimension, such as time, preference, cost or causality (e.g. Tversky, 1995, 2001).

Graphics portraying things that are essentially visual are inventions that are ancient and widespread across many cultures. Graphics that use figures of depiction to convey abstract concepts are also ancient. In fact, the origins of written language are in pictures. In contrast, graphics that use space to convey nonspatial relations are, for the most part, recent Western inventions (e.g. Beniger \& Robyn, 1978; Tufte, 1983; Carswell \& Wickens, 1988). Given that graphics can portray elements and relations that are not spatial as well as those that are spatial, their efficacy in learning and communication should be, and is, broad. In fact, it seems that it is difficult to capture the vast literature on effects of diagrams on learning with a summary less general than graphics aid learning when they present the same information as text in a different format and also when they present information complementary to textual information (e.g., Levie \& Lentz, 1982).

\subsection{NATURAL COGNITIVE CORRESPONDENCES IN GRAPHICS: THE CONGRUENCE PRINCIPLE}

The benefits of graphics are apparent from their ubiquity and in their naturalness. By naturalness, we mean a convergence of inventions across cultures and ages for using space to represent space and to represent abstract concepts that suggest cognitive correspondences between mental spaces and real ones. The pictorial languages and petroglyphs found all over the world are one example (e.g. Mallery, 1893/1972; Gelb, 1963; Harley \& Woodward, 1987, 1992; Coulmas, 1989; DeFrancis, 1989; Woodward \& Lewis, 1994). The manner of schematizing people, animals, rivers, mountains, foods and houses bear striking similarities across cultures. Interestingly, these early written communications resemble contemporary attempts at inventing writing by preliterate children (Kellogg, 1969; Goodnow, 1977; Tolchinsky-Landsman \& Levin, 1987). Similarities in cross-cultural and developmental attempts to externalize mathematical concepts have been observed by Hughes (1986) and for geographic concepts, especially depictions of hills, by Wood (1992). For the most part, these graphic communications have used pictorial elements. Use of spatial relations to express temporal, quantitative and preference relations was evident in children as young as 5 and in children from diverse cultures (Tversky, Kugelmass \& Winter, 1991). Use of space has been systematic across young inventors who have used primarily horizontal and vertical lines, with increases going upwards or to left or right. Inventors young and old naturally map increasing rates onto increasing slopes (Gattis \& Holyoak, 1996; Gattis, 2001). These natural cognitive correspondences are captured in the Congruence Principle for effective graphics: the structure and content of the external representation should correspond to the desired structure and content of the internal representation.

\subsection{GRAPHICS GOOD AND NOT SO GOOD}

With recent rapid advances in technology and with increasing contact among cultures not sharing spoken languages, graphic devices have proliferated. However, the 
advances in the technology of producing attractive graphics often seem to drive and outstrip the development of tools and devices rather than research on their utility. Graphics are not always effective, or put differently, not all graphics are effective in all situations. In fact, the early research comparing learning with graphics to learning with text alone gave mixed results, often in spite of enthusiasm for the pictorial devices (see reviews by Levin \& Lesgold, 1978; Levie \& Lentz, 1982; Mandl \& Levin, 1989). Moreover, much of the early research used global comparisons between media and did not address the subtler questions of what accounted for the facilitation when it occurred. As research progressed, the types of situations, graphics, tasks and learners for which graphics are effective has become clearer. Three-dimensional displays are a new case in point. They seem to be everywhere, or at least in software packages, and they do seem to be liked (Carswell, Frankenberger \& Bernhard, 1991; Levy, Zacks, Tversky \& Schiano, 1996). However, it is simply not clear if 3D displays improve performance, speed, accuracy or memory for data (Carswell et al., 1991; Spence \& Lewandowsky, 1991; Levy et al., 1996). In some tasks, for example, memory, there is little difference between 3D and 2D displays; in other tasks, for example, estimation, there is a disadvantage to 3D displays (Zacks, Levy, Tversky \& Schiano, 1998).

\subsection{ANIMATION}

Another of the newer, attractive graphic devices is animation. On the surface, animation is compelling. By the Congruence Principle, it should be a natural for conveying concepts of change, just as space in graphics is a natural for conveying actual space. Animation should, in principle, be effective for expressing processes such as weather patterns or circuit diagrams or the circulatory system or the mechanics of a bicycle pump. And, just as real space is effective for conveying metaphoric space, real change should be a natural for conveying metaphoric change, such as the spread of cultural inventions like writing, agriculture or metallurgy, the transmission of control in an organization, or the changes in production of various industries over time. Given the breadth of concepts for which animation seems appropriate and the increasing accessibility of computer tools for animating, the enthusiasm for animation is understandable.

\subsection{PREVIEW}

With this background on graphics in mind, we will selectively review research on animation (see Betrancourt \& Tversky, 2000). "Selectively" because some of what has been called animation has involved other aspects of communication situations, especially interactivity, which is known to benefit learners on its own (e.g. Ferguson \& Hegarty, 1995). To evaluate animation per se, it must be compared to graphics that do not change with time, as it is change with time that animation adds. The review focuses on uses of animation to teach complex systems, mechanical, biological, physical, operational, computational. It is in this context that most of the evaluations of animation have been done. There are other uses of animation, especially in computer interfaces, and these will be considered briefly at the end. This review will not 
provide encouragement for the enthusiasm for animation. That leaves us with a need to explain why animation has not produced the expected benefits. To account for the failures of animation, we step back and take a closer look at how people perceive and comprehend real animations. With human perceptual and cognitive limitations in mind, we turn again to the basic question: When will animation be effective?

\subsection{KINDS OF ANIMATIONS}

Of course, change over time occurs in many different ways, and hence is conveyed by animations differing in complexity. Perhaps the simplest movement is a path or trajectory. This can be animated as the movement of a dot, providing that the features of the moving object are not relevant. Representing the speed and manner of the moving object may require richer animations. Sometimes what needs to be conveyed is more complex than a path, for example, the movement of parts of an object or system with respect to each other. The movement or change of either a path or a system may be in two or three dimensions. In these cases, movement is of the object or system itself. In other cases, the object or system may be stationary, and the movement is of the viewpoint of the observer, in order to show other aspects of the object or system. The critical information to be conveyed determines the form of the animation. But, whatever the form, in order to be effective, an animation must be perceived and comprehended adequately. Clearly, complexity challenges both.

\section{Selective review of research on animation}

\subsection{INCOMPARABLE CONTENT IN STATIC AND ANIMATED GRAPHICS}

In order to know if animation per se is facilitatory, animated graphics must be compared to informationally equivalent static graphics. That way, the contributions of animation can be separated from the contributions of graphics alone without confounding with content. There may be cases where this control is difficult to instantiate, for example, for an animation that shows a complex manner of motion where both spatial position and timing are of the essence. However, the cases of incomparability reviewed here were not that subtle. They are all cases where the static graphics could have conveyed the same information as the animated ones. Showing that students learn material better when it is presented than when it is not presented should not be a goal of empirical research.

An elegant use of animation is a pair of moving dashed lines to illustrate differences in speed for rate X time = distance problems (Baek \& Layne, 1988). In this animation, the irrelevant aspects of the situation were eliminated, and the essential aspects reduced to dashes moving proportional to speed. Although students learning from the animation outperformed those learning from a static diagram, little can be concluded about animation as such. The static diagram was far from equivalent to the animated one; in particular, it did not take advantage of spatial distance to convey problem distance. Essentially, the static graphic was a table listing two sets of distances, times 
and average speeds. Thus, there is no way of knowing if the animated graphic produced benefits beyond a comparable static graphic.

Lack of comparability of static and animated diagrams obviate conclusions about the benefits of animation in other studies. In a study evaluating graphics for teaching the circulatory system, the animated diagrams of the heart included blood pathways, but the static diagram did not (Large, Beheshti, Breuleux \& Renaud, 1996). The static graphics used in Rieber's (1990, 1991 $a, b)$ computer-based lesson on Newton's laws of motion did not include information fundamental to understanding the laws. The static graphic for Newton's law of equal and opposite forces depicted the movement of the ball, but not that a single kick to the ball both started and stopped its motion. The concept of inertia is critical to understanding this law, yet can only be extracted from the accompanying text. The animated diagram, in contrast, showed each kick as it started and stopped the ball's motion. Although Large and colleagues and Rieber believe their findings support the use of animated graphics, the lack of equivalence of the static and animated graphics call this conclusion into question.

At first glance, for other studies evaluating static and animated graphics, the graphics appear comparable. But on close examination, the animated graphics present information not available in the static versions, in particular the details of the microsteps between larger steps; that is, the minute spatial-temporal actions of components. Events such as those portrayed in animations can be reliably segmented into coarser and finer units by observers (Zacks, Tversky \& Iyer, 2001). For the most part, the coarse units are segmented by objects or object parts and the fine units by different fine-grained actions on the same object or part. Many of the static graphics portray only the coarse segments whereas the animations portray both the coarse and fine segments. Thus, there is greater. information in the animations than in the static displays. Any benefits, then, may be due to the added information alone rather than the format of the graphics, information that could easily have been conveyed in the static graphics.

In a study evaluating students' ability to learn the operation and troubleshooting of an electronic circuit from a static graphic or from an animated graphic, Park and Gittelman (1992) report better performance in the animated graphic condition. Although both graphics, static and animated, showed the relationships between components in the process, only the animated graphic showed the fine structure. Specifically, when an action was taken with the circuit, the animation depicted the finegrained actions of the components. The static graphic showed the spatial relationships among the components but did not portray the mechanics of the circuit's response to a particular action and the consequent change in the circuit state.

Research by Thompson and Riding (1990) further supports the hypothesis that animation facilitates learning when it presents the fine-grained actions that static graphics do not present. Their program taught the Pythagorean theorem to junior high school students. The graphic depicted a triangle and three squares, where each square shared one of the triangle's sides. Using shears and rotations, the program showed that the area of the square along the hypotenuse was the same as the combined areas of the two other squares. One group viewed a static graphic, a second group saw a discrete animation of the steps shown on the paper graphic, and a third group saw a continuous 
animation of the steps. The group viewing the continuous animation outperformed the other two graphic groups.

However, the results cannot be taken as showing the superiority of animated over static graphics as the authors explicitly state that the information on the paper graphic was equivalent to the discrete animation, but not equivalent to the continuous animation. The continuous animation depicted all the lower level actions, while that information had to be inferred from both of the other graphics.

\subsection{INCOMPARABLE PROCEDURES IN STATIC AND ANIMATED GRAPHICS}

The lack of equivalent information in static and animated graphics is not the only difficulty in assessing possible benefits from animation. Other studies comparing animation have not used equivalent procedures. In some studies, the animation condition allowed interactivity while the static condition did not, so that benefits may be due to interactivity rather than animation (e.g. Schnotz \& Grzondziel, 1999). Another factor known to facilitate learning, prediction, has also been confounded with animation in some studies. In prediction, participants anticipate outcomes, and then view graphics (or read text) to check if their predictions were fulfilled. And, indeed, conditions that involve both animation and prediction of a mechanical system did yield benefits beyond graphics that allow neither (Hegarty, Quilici, Narayanan, Holmquist \& Moreno, 1999). Because prediction alone is known to facilitate learning, facilitation cannot be attributed to animation. Later studies by the same group showed no benefits of animation per se in understanding the workings of a flushing cistern (Hegarty, Narayanan \& Freitas, in press). Kieras (1992) investigated the effects of animated and static graphics on students' ability to understand the operation of an energy system, the "Star Trek Phaser Bank". Students studied conceptual information about the system in the form of text or in the form of static or animated diagrams. Students who learned from the animated graphic performed significantly better on firing the phaser and diagnosing malfunctions tasks than those who learned from a static graphic or lacked a graphic. Students with the static or animated graphics, however, were allowed to use the graphics during the test phase of the experiment. The presence of graphics during the test phase makes the task one of reading graphics rather than using the information contained in the graphics. That is, the animated graphic may be facilitating execution of the task rather than understanding of the concepts.

Nathan, Kintsch and Young (1992) developed an animated interactive program ("Animate") to help students comprehend algebra word problems. The program is designed to facilitate understanding of the relationship between the formal mathematics of a word problem and the situation described in the problem. Students in the Animate condition wrote a formal equation to solve the problem and then animated the equation to see if it depicted the expected solution. None of the other conditions included graphics and two of the three conditions had interfaces substantially different from the Animate interface. Although performance in the Animate condition was better than in the other three conditions, the lack of comparability among conditions does not allow any conclusions about the relative efficacy of animated graphics. 


\subsection{FAILURES OF ANIMATION TO BENEFIT}

When examined carefully, then, many of the so-called successful applications of animation turn out to be a consequence of a superior visualization for the animated than the static case, or of superior study procedures such as interactivity or prediction that are known to improve learning independent of graphics. In addition, the literature is filled with outright failures to find benefits of animation, even when animation is in principle ideal: for conveying change over time (e.g. Schnotz \& Grondziel, 1999). Morrison and Tversky (2001) compared text with text coupled with either static or animated graphics in a task teaching permissible social paths among people or navigation paths among objects. Graphics yielded better performance than text alone, but only for low spatial ability participants. Across all participants, diagrams that animated the path provided no benefit beyond that of the individual static diagrams. Rieber and Hannafin (1988) and Rieber (1989) found no facilitation for animation in teaching Newton's laws of motion to elementary school students. In one case, both text and animation were used as orienting activities prior to the presentation of each section of the lesson (Rieber \& Hannafin, 1988), neither of which had any effect. In the second case, elaborating the textual lesson with additional text and/or no, static, or animated graphics did not lead to performance differences (Rieber, 1989). Rieber, Boyce and Assad (1990) used the same design to evaluate the performance of college students when learning Newton's laws. As with the earlier experiments there was no effect of graphic condition. Additionally, providing different forms of practice, one involving interactive animation, had no effect in any of the three experiments.

Students learning about the production of growth hormones during biotechnology were presented with text alone, a static diagram, or an animated diagram (ChanLin, 1998). When learning procedural information, such as the formation of a peptide chain, the students viewed a single static diagram which combined information about all the steps in the process. Students in the animation group viewed a series of individual animations depicting each step of the process. Students in both conditions performed equally well. In fact, the only difference was between the static and no diagram condition for those students who had a background in biology. All other conditions, for both biology and non-biology students, were equal in terms of performance.

As a supplement to a biology course they were taking, junior high students interacted with the Advanced Computing for Science Education (ACSE) environment, which is a multimedia program incorporating textual information, still graphics, movies, and simulations (Pane, Corbett \& John, 1996). Students using the ACSE program did not perform better than students using static graphics except for a slight advantage for information presented only in the ACSE program and not during the biology course lectures.

Byrne, Catrambone and Stasko (1999) tested the effectiveness of animated graphics in teaching college students computer algorithms, specifically depth-first searches and binomial heaps. The authors were discouraged to find that the benefits of viewing animated graphics were equivalent to making predictions about the outcomes of the algorithms when provided with static graphics.

Animated graphics are often employed to teach students how to use a computer or a computer program. This is also an area where these animations do not appear to be 
effective. Three groups of researchers investigated the role of animation in teaching students how to use a Macintosh ${ }^{\circledR}$ computer, how to use the MacDraw ${ }^{\circledR}$ graphics editor, and how to use HyperCard ${ }^{\circledR}$ (Payne, Chesworth, \& Hill, 1992; Dyck, 1995; Harrison, 1995, respectively). In each case, presenting any type of a graphic, static (only for Harrison, 1995) or animated, facilitated performance when compared to providing no instruction. Students in the animated graphic conditions did not outperform those in the equivalent text (Payne, Chesworth \& Hill, 1992; Dyck, 1995) or static graphic (Harrison, 1995) conditions.

Palmiter and colleagues compared animated and still graphics for teaching students how to use an on-line help system for Hypercard ${ }^{\mathbb{R}}$ (Palmiter, Elkerton \& Baggett, 1991; Palmiter \& Elkerton, 1993). Although the students using the animation completed the training task more quickly, they completed the testing task more slowly. Moreover, after a week, performance of students who had studied the text improved, but performance for those who had studied the animation declined. The long-term facilitation of text over animation was attributed to deeper processing of the text than of the animation.

Thus, most, if not all, of the successes of animation seem to be due to advantages in extra information conveyed or additional procedures, rather than the animation of the information per se. Animations are often interactive; interactivity is known to facilitate performance but it should not be confused with animation (e.g. Ferguson \& Hegarty, 1995). When animations fail to benefit learning, their promoters argue that they are attractive and motivating, so they could be preferred just for that (Perez \& White, 1985; Rieber, 1991a; Sirikasem \& Shebilske, 1991). However, it turns out that animations frequently take more time, so they have a cost. Even more damaging to the motivation hypothesis is that animations are not universally preferred, and are often not used (e.g. Pane et al., 1996). Finally, and to foreshadow our next point, many animations, even elegant and natural ones, are difficult to perceive and understand, except perhaps by experts with extensive experience (e.g. Lowe, 1999; Slocum, Yoder, Kessler \& Sluter, 2000). The consequence of this is that animations may be distracting, or even harmful, to conveying important ideas. Providing animated weather maps to novices, for example, only encouraged them to attend to perceptually salient information. They were unable to use the animations to extract thematically important information, especially the causal information that underlies adequate mental models of the system (Lowe, 1999).

\section{Why do animations fail? The Apprehension Principle}

The many failures to find benefits of animation even in conveying change over time, a concept that seems ideally suited to animation is surprising, indeed, disappointing, and calls for deeper inquiry into information processing of animation. The drawback of animation may not be the cognitive congruence between the conceptual material and the visual presentation but rather perceptual and cognitive limitations in the processing of a changing visual situation. Effective graphics should conform not only to the Congruence Principle, but also to the Apprehension Principle: the structure and content 
of the external representation should be readily and accurately perceived and comprehended.

\subsection{ANIMATIONS MAY BE HARD TO PERCEIVE}

Generations of masterpieces in galleries and museums all over the world portray the legs of galloping horses incorrectly. Before stop-gap photography, the complex interaction of horses' legs simply happened too fast to be accurately apprehended. Even when motion is simplified to the path or trajectory of a single object rather than the complex interaction of moving parts, perception of motion may not be accurate. Sketches of the trajectories of pendula, propelled objects and dropped objects by novices and experts alike are often incorrect, apparently governed more by Gestalt-like perceptual principles than laws of physics (e.g. Caramazza, McCloskey \& Green, 1981; McCloskey, 1983a, b; Kaiser, Proffitt, Whelan \& Hecht, 1992; Freyd \& Jones, 1994). Paths of moving objects, for example, are perceived as closer to horizontal or vertical than they actually are (Shiffrar \& Shepard, 1991; Pani, Jeffres, Shippey \& Schwartz, 1996). For some kinds of motion, observers can select the correct path from an animation, but still reproduce it incorrectly (Kaiser et al., 1992).

\subsection{ANIMATIONS MAY BE COMPREHENDED DISCRETELY}

Even when actual motion is smooth and continuous, people may conceive of it as composed of discrete steps [e.g. Hegarty, 1992; Zacks et al., 2001; but see Schwartz (1999) and Schwartz \& Black (1996) for evidence that for atomic substeps that are analog in nature, such as the turning of gears, mental animation may be analog as well]. If motion is conceived of in discrete steps instead of continuously, then the natural way of conveying it is to portray it in discrete steps rather than in a continuous animation. This is quite common in pictorial instructions for complex motion, such as operating a machine or assembling an object, where each step is portrayed in a separate frame and the frames are ordered by the sequence of steps. For simple motion, as in the path of an object or the flow of control or electricity through a system, a single diagram can convey the path, indicated by lines and arrows. In addition to corresponding to the way people conceive of animations, multiple diagrams have an additional advantage: they easily allow comparison and reinspection of the details of the actions. By contrast, animations are fleeting, they disappear, and when they can be reinspected they usually are reinspected in motion, where it may be difficult to perceive all the minute changes simultaneously.

\subsection{INTERACTIVITY}

Clearly, interactivity, a factor known to facilitate learning, can help overcome the difficulties of perception and comprehension. Stopping, starting and replaying an animation can allow reinspection, focusing on specific parts and actions. Animations that allow close-ups, zooming, alternative perspectives, and control of speed are even more likely to facilitate perception and comprehension. Of course, the proper experiments have yet to be done, for example, static graphics also allow close-ups 
and perspective switches. Careful studies will reveal the particular aspects, if any, of animation and interactivity that facilitate conveying specific concepts.

\subsection{CAVEATS}

The work analyzed here is work on the role of animations teaching complex systems, mechanical, biological, computational. The conclusions are restricted to those situations. Animations are used in many other situations. Common uses of animation include concrete applications such as walks through environments as well as abstract uses such as the fill bar indicating the rate of completion of a file download (see Card, Mackinlay \& Shneiderman, 1999, for examples). Although rarely tested in highly controlled experiments [see Tan, Robertson, \& Czerwinski (2001) for an exception that uses animation to convey changes in orientation], these uses of real time animation to convey change in time and space have perhaps passed the test of time. They have appeared in many interfaces for many years; one would think that if they caused problems, user testing and complaints would have eliminated them (this said with hesitation, as unfortunate features have been known to survive, and lamented, e.g. Norman, 1988). At this point then, the most promising uses of animation seem to be to convey real-time changes and reorientations in time and space.

\section{Implications}

Given the analysis of the difficulty of perceiving and conceptualization animations, the failures to find benefits of animation for conveying complex systems beyond equivalent static diagrams is less perplexing. The apparent successes turned out not to be successes. In those cases, the animated graphics in fact were not equivalent to the static graphics, that is, in the animated graphics, more information was presented or the same information was presented differently, better, in the animated than in the static graphics. In other studies, animation was confounded with other factors known to facilitate learning, interactivity or prediction or even the presence of graphics. In some of the most carefully controlled cases, the animations conveyed detailed information about the fine structure of the processes that was not available in the static graphics. It may be that some kinds of information are more easily conveyed in animations than in static diagrams, and that would be sufficient reason for using them. The information that might be more effectively portrayed in an animated graphic might include the qualitative aspects of motion or the microsteps, the exact sequence and timing of complex operations. Whether animations are more effective than static graphics for these subtle aspects of change over time is unknown.

This analysis suggests two principles specifying conditions for successful animated graphics, though these principles do not guarantee that animated graphics will be superior to equivalent static ones.

Congruence Principle: The structure and content of the external representation should correspond to the desired structure and content of the internal representation. For example, since routes are conceived of as a series of turns, an effective external visual representation of routes will be based on turns. 


\begin{abstract}
Apprehension Principle: The structure and content of the external representation should be readily and accurately perceived and comprehended. For example, since people represent angles and lengths in gross categories, finer distinctions in diagrams will not be accurately apprehended. In the case of routes, exact angles of turns and lengths of roads are not important.
\end{abstract}

To accord with the Principle of Congruence, there should be a natural correspondence between change over time, the core of animation, and the essential conceptual information to be conveyed. That conceptual information could be change over time, for example movement or transformation or process. It could also be temporal sequence or causal flow. It could even be a natural order for attending to a complex array (Betrancourt \& Tversky, in press). Some of these changes and processes will be naturally more discrete, some more continuous. To accord with the Principle of Apprehension, animations must be slow and clear enough for observers to perceive movements, changes, and their timing, and to understand the changes in relations between the parts and the sequence of events. This means that animations should lean toward the schematic and away from the realistic, an inclination that does not come naturally to many programmers, who delight in graphic richness and realism. It also may mean annotation, using arrows or highlighting or other devices to direct attention to the critical changes and relations. Schematizing is simpler than it sounds; clear understanding is a prerequisite to including only the information essential to the processes to be conveyed and eliminating extraneous but sometimes appealing information.

According to this analysis, if there are benefits to animation, they should be evident especially for continuous rather than discrete changes, in particular, for manner of change and for microsteps, the subtle and intricate timing relations among parts of a complex system. However, even for these cases, clever schematization of static diagrams may be just as effective as animation. For example, arrows are effective in indicating temporal sequence and direction of motion (e.g. Tversky, Zacks, Lee \& Heiser, 2000).

Interactivity may be the key to overcoming the drawbacks of animation as well as enhancing its advantages. If learners are in control of the speed of animation and can view and review, stop and start, zoom in and out, and change orientation of parts and wholes of the animation at will, then the problems of veridical perception can be alleviated. Participants can study those aspects of the animation that they need without suffering through portions they already understand. Then, carefully crafted animations can be apprehended, those that highlight the discrete and high-level steps and those that depict the analog and microsteps that animations seem well-suited to portray and convey. Like all good things, animation must be used with care.

Preparation of the manuscript and part of the research reported here were aided by Office of

Naval Research Grants Number NOOO14-PP-1-0649 and NOOO140110717 to Stanford University.

\title{
References
}

BAeK, Y. K. \& LAYNe, B. H. (1988). Color, graphics, and animation in a computer-assisted learning tutorial lesson. Journal of Computer-Based Instruction, 15, 131-135. 
Betrancourt, M. \& Tversky, B. (2000). Effects of computer animation on users'performance: a review. Le travail humain, 63, 311-329.

Betrancourt, M. \& Tversky, B. (in press). Simple animations for organizing diagrams. International Journal of Human Computer Studies.

Bauer, M. I. \& Johnson-Laird, P. N. (1993). How diagrams can improve reasoning. Psychological Science, 6, 372-378.

Beniger, J. R. \& Robyn, D. L. (1978). Quantitative graphics in statistics. The American Statistician, 32, 1-11.

Bower, G. H. (1970). Analysis of a mnemonic device. American Scientist, 58, 496-510.

Byrne, M. D., Catrambone, R. \& Stasko, J. T. (1999). Evaluating animations as student aids in learning computer algorithms. Computers \& Education, 33, 253-278.

Caramazza, A., McCloskey, M. \& Green, B. (1981). Naive beliefs in "sophisticated" subjects: misconceptions about trajectories of objects. Cognition, 9, 117-123.

Card, S. K., Mackinlay, J. D. \& Shneiderman, B. Eds. (1999). Readings in Information Visualization: Using Vision to Think. San Francisco: Morgan Kaufmann.

Carswell, C., Frankenberger, S. \& Bernhard, D. (1991). Graphing in depth: perspectives on the use of three-dimensional graphs to represent lower-dimensional data. Behaviour and Information Technology, 10, 459-474.

Carswell, C. M. \& Wickens, C. D. (1988). Comparative graphics: history and applications of perceptual integrality theory and the proximity compatibility hypothesis. Technical Report, Institute of Aviation, University of Illinois at Urbana-Champaign.

ChanLin, L.-J. (1998). Animation to teach students of different knowledge levels. Journal of Instructional Psychology, 25, 166-175.

Coulmas, F. (1989). The Writing Systems of the World. Oxford: Basil Blackwell.

Cooper, W. E. \& Ross, J. R. (1975). World order. In R. E. Grossman, L. J. San \& T. J. Vance, Eds. Papers from the Parasession on Functionalism. Chicago: Chicago Linguistic Society.

DeFrancis, J. (1989). Visible Speech: The Diverse Oneness of Writing Systems. Honolulu: University of Hawaii Press.

De Loach, J. S., Miller, K. F. \& Rosengren, K. S. (1997). The credible shrinking room: Very young children's performance with symbolic and non-symbolic relations. Psychological Science, 8, 308-313.

Dwyer, F. M. (1978). Strategies for Improving Visual Learning. State College, PA: Learning Services.

DYCK, J. L. (1995). Problem solving by novice Macintosh users: the effects of animated, selfpaced written, and no instruction. Journal of Educational Computing Research, 12, 29-49.

Ferguson, E. L. \& Hegarty, M. (1995). Learning with real machines or diagrams: application of knowledge to real-world problems. Cognition and Instruction, 13, 129-160.

Fontaine, S. (2001). Spatial cognition and the processing of verticality in underground environments. In D. Montello \& M. Hegarty, Eds. Spatial Information Theory. Berlin: Springer.

Freyd, J. J. \& Jones, K. T. (1994). Representational momentum for a spiral path. Journal of Experimental Psychology: Learning, Memory, and Cognition, 20, 968-976.

GatTis, M. (2001). Reading pictures: constraints on mapping conceptual and spatial schemas. In M. Gattis, Ed. Spatial Schemas in Abstract Thought, pp. 223-245. Cambridge: MIT Press.

Gattis, M. \& HolyoAK, K. J. (1996). Mapping conceptual to spatial relations in visual reasoning. Journal of Experimental Psychology: Learning, Memory, and Cognition, 22, 1-9.

Gelb, I. (1963). A Study of Writing (2nd edn). Chicago: University of Chicago Press.

Gobert, J. D. (1999). Expertise in the comprehension of architectural plans. In J. Gero \& B. Tversky, Eds. Visual and Spatial Reasoning in Design, pp. 185-205. Sydney, Australia: Key Centre of Design Computing and Cognition.

Goodnow, J. (1977). Children Drawing. Cambridge: Harvard University Press.

Harley, J. B. \& Woodward, D. Eds. (1987). The History of Cartography: Cartography in Prehistoric, Ancient and Medieval Europe and the Mediterranean, Vol. 1. Chicago: University of Chicago Press. 
Harley, J. B. \& Woodward, D. Eds. (1992). The History of Cartography: Cartography in the Traditional Islamic and South Asian Societies, Vol. 2, Book 1. Chicago: University of Chicago Press.

HARrison, S. M. (1995). A comparison of still, animated, or nonillustrated on-line help with written or spoken instructions in a graphical user interface. In I. R. KATZ, R. MACK, L. Marks, M. B. Rosson \& J. Nielsen, Eds. Proceedings of the ACM Conference on Human Factors in Computing Systems, pp. 82-89. Denver, CO: ACM.

Hegarty, M. (1992). Mental animation: Inferring motion from static displays of mechanical systems. Journal of Experimental Psychology: Learning, Memory, and Cognition, 18, $1084-1102$.

Hegarty, M., Narayanan, N. H. \& Freitas, P. (in press). Understanding machines from multimedia and hypermedia presentations. In J. Otero, J. A. Leon \& A. Graesser, Eds. The Psychology of Science Text Comprehension. Hillsdale, NJ: Lawrence Erlbaum.

Hegarty, M., Quilici, J.Narayanan, N. H., Holmquist, S. \& Moreno, R. (1999). Designing multimedia manuals that explain how machines work: Lessons from evaluation of a theorybased design. Journal of Educational Multimedia and Hypermedia, 8, 119-150.

Hughes, M. (1986). Children and Number: Difficulties in Learning Mathematics. Oxford: Blackwell.

Kaiser, M. K., Proffitt, D. R., Whelan, S. M. \& Hecht, H. (1992). Influence of animation on dynamical judgments. Journal of Experimental Psychology: Human Perception and Performance, 18, 669-690.

Kellogg, R. (1969). Analyzing Children's Art. Palo Alto, CA: National Press.

KIERAS, D. E. (1992). Diagrammatic displays for engineered systems: effects on human performance in interacting with malfunctioning systems. International Journal of Man-Machine Studies, 36, 861-895.

Large, A., Beheshti, J., Breuleux, A. \& Renaud, A. (1996). The effect of animation in enhancing descriptive and procedural texts in a multimedia learning environment. Journal of the American Society for Information Science, 47, 437-448.

LARKin, J. H. \& Simon, H. A. (1987). Why a diagram is (sometimes) worth ten thousand words. Cognitive Science, 11, 65-99.

Levie, W. H. \& Lentz, R. (1982). Effects of text illustrations: a review of research. Educational Communication and Technology, 30, 195-232.

Levin, J. R. \& Lesgold, A. M. (1978). On pictures in prose. Educational Communication and Technology, 26, 233-243.

Levin, J. R. \& MAYER, R. E. (1993). Understanding illustrations in text. In B. K. BRitton, A. Woodward \& M. Binkley, Eds. Learning from Textbooks: Theory and Practice, pp. 95-119. Hillsdale, NJ: Erlbaum.

Levy, E., Zacks, J., Tversky, B. \& Schiano, D. (1996). Gratuitous graphics: Putting preferences in perspective. Proceedings of the ACM Conference on Human Factors in Computing Systems, pp. 42-49. New York: ACM.

Liben, L. S. (1999). Developing an understanding of external spatial representations. In I. E. Sigel, Ed. Development of Mental Representation pp. 297-321. Mahwah, NJ: Erlbaum Associates.

LowE, R. (1999). Extracting information from an animation during complex visual processing. European Journal of the Psychology of Education, 14, 225-244.

Mallery, G. (1893/1972). Picture Writing of the American Indians (Originally published by Government Printing Office). New York: Dover.

Mandl, A. \& Levin, J. Eds. (1989). Knowledge Acquisition from Text and Pictures. Amsterdam: North-Holland.

MAYER, R. E. (1989). Systematic thinking fostered by illustrations in scientific text. Journal of Educational Psychology, 81, 240-46.

McCloskey, M. (1983a). Intuitive physics. Scientific American, 248, 122-130.

McCloskey, M. (1983b). Naive theories of motion. In D. Gentner \& A. L. Stevens, Eds. Mental Models, pp. 299-324. Hillsdale, NJ: Erlbaum. 
Morrison, J. B. \& Tversky, B. (2001). The (in)effectiveness of animation in instruction. In J. JACKO \& A. SeArs, Eds. Extended Abstracts of the ACM Conference on Human Factors in Computing Systems, pp. 377-378. Seattle: ACM.

Nathan, M. J., Kintsch, W. \& Young, E. (1992). A theory of algebra-word-problem comprehension and its implications for the design of learning environments. Cognition and Instruction, 9, 329-389.

Norman, D. A. (1988). The psychology of Everyday Things. NY: Basic Books.

Palmiter, S. \& Elkerton, J. (1993). Animated demonstrations for learning procedural computer-based tasks. Human-Computer Interaction, 8, 193-216.

Palmiter, S. L., Elkerton, J. \& Baggett, P. (1991). Animated demonstrations vs. written instructions for learning procedural tasks: a preliminary investigation. International Journal of Man-Machine Studies, 34, 687-701.

Pane, J. F., Corbett, A. T. \& John, B. E. (1996). Assessing dynamics in computer-based instruction. In M. J. TAuBER, Ed. Proceedings of the ACM Conference on Human Factors in Computing Systems, pp. 797-804. Vancouver: ACM.

Pani, J. R., Jeffres, J. A., Shippey, G. T. \& Schwartz, K. T. (1996). Imagining projective transformations: Aligned orientations in spatial organization. Cognitive Psychology, 31, $125-167$.

Park, O.-C. \& Gittelman, S. S. (1992). Selective use of animation and feedback in computerbased instruction. Educational Technology, Research, and Development, 40, 27-38.

Payne, S. J., Chesworth, L. \& Hill, E. (1992). Animated demonstrations for exploratory learners. Interacting with Computers, 4, 3-22.

Perez, E. C. \& White, M. A. (1985). Student evaluation of motivational and learning attributes of microcomputer software. Journal of Computer-Based Instruction, 12, 39-43.

Rieber, L. P. (1989). The effects of computer animated elaboration strategies and practice on factual and application learning in an elementary science lesson. Journal of Educational Computing Research, 5, 431-444.

RIEBER, L. P. (1990). Using computer animated graphics with science instruction with children. Journal of Educational Psychology, 82, 135-140.

Rieber, L. P. (1991a). Animation, incidental learning, and continuing motivation. Journal of Educational Psychology, 83, 318-328.

RIEBER, L. P. (1991b). Effects of visual grouping strategies of computer-animated presentations on selective attention in science. Educational Technology, Research, and Development, 39, $5-15$.

Rieber, L. P., Boyce, M. J. \& Assad, C. (1990). The effects of computer animation on adult learning and retrieval tasks. Journal of Computer-Based Instruction, 17, 46-52.

Rieber, L. P. \& Hannafin, M. J. (1988). Effects of textual and animated orienting activities and practice on learning from computer-based instruction. Computers in the Schools, 5, 77-89.

SCAIFe, M. \& Rogers, Y. (1996). External cognition: how do graphical representations work? International Journal of Human-Computer Studies, 45, 185-213.

Schmandt-Besserat, D. (1992). Before Writing: From Counting to Cuneiform, Vol. 1. Austin: University of Texas Press.

Schnotz, W. \& Grzondziel, H. (1999). Individual and co-operative learning with interactive animated pictures. European Journal of Psychology of Education, 14, 245-265.

Schnotz, W. \& Kulhavy, R. W. (1994). Comprehension of Graphics. Amsterdam: Elsevier.

Schwartz, D. L. (1999). Physical imagery: kinematic vs. dynamic models. Cognitive Psychology, 38, 433-464.

Schwartz, D. L. \& Black, J. B. (1996). Analog imagery in mental model reasoning: depictive models. Cognitive Psychology, 30, 154-219.

Shiffrar, M. M. \& Shepard, R. N. (1991). Comparison of cube rotations around axes inclined relative to the environment or to the cube. Journal of Experimental Psychology: Human Perception and Performance, 17, 44-54

Sirikasem, P. \& Shebilske, W. L. (1991). The perception and metaperception of architectural designs communicated by video-computer imaging. Psychological Research/Psychologische Forschung, 53, 113-126. 
Slocum, T. A., Yoder, S. C., Kessler, F. C. \& Sluter, R. S. (2000). MapTime: software for exploring spatiotemporal data associated with point locations. Cartographica, 57, 15-31.

Small, J. P. (1997). Wax Tablets of the Mind: Cognitive Studies of Memory and Literacy in Classical Antiquity. New York: Routledge.

Spence, I. \& Lewandowsky, S. (1991). Displaying proportions and percentages. Applied Cognitive Psychology, 5, 61-77.

TAn, D. S., Robertson, G. G. \& Czerwinski, M. (2001). Exploring 3D navigation: combining speed-coupled flying with orbiting. In J. JaCko, A. SEARs, M. Beaudouin-Lafon, \& R. J. K. JACOB, Eds. Proceedings of the ACM Conference on Human Factors in Computing Systems, pp. 418-424. Seattle: ACM.

TAYlor, H. A. \& TVersky, B. (1992). Spatial mental models derived from survey and route descriptions. Journal of Memory and Language, 31, 261-292

Tessler, S., Iwasaki, Y. \& Kincho Law, K. (1995). Qualitative structural analysis using diagrammatic reasoning. In J. Glasgow, N. H. NARAYANAn \& G. Chandrasekeran, Eds. Diagrammatic Reasoning: Cognitive and Computational Perspectives, pp. 711-730. Cambridge: MIT Press.

Thompson, S. V. \& Riding, R. J. (1990). The effect of animated diagrams on the understanding of a mathematical demonstration in 11- to 14-year-old pupils. British Journal of Educational Psychology, 60, 93-98.

TolChINSKY-LANDSMANN, L. \& Levin, I. (1987). Writing in four- to six-year-olds: representation of semantic and phonetic similarities and differences. Journal of Child Language, 14, $127-144$.

Tufte, E. R. (1983). The Visual Display of Quantitative Information. Cheshire, CT: Graphics Press.

Tversky, B. (1995). Cognitive origins of conventions. In F. T. MARchese, Ed. Understanding Images, pp. 29-53. New York: Springer-Verlag.

Tversky, B. (2001). Spatial schemas in depictions. In M. Gattis, Ed. Spatial Schemas and Abstract Thought, pp. 79-111. Cambridge: MIT Press.

Tversky, B., Kugelmass, S. \& Winter, A. (1991). Cross-cultural and developmental trends in graphic productions. Cognitive Psychology, 23, 515-557.

Tversky, B, Zacks, J., Lee, P. U. \& Heiser, J. (2000). Lines, blobs, crosses, and arrows: Diagrammatic communication with schematic figures. In M. Anderson, P. Cheng, \& V. HaArslev, Eds. Theory and Application of Diagrams, pp. 221-230. Berlin: Springer.

WinN, W. (1987). Charts, graphs, and diagrams in educational materials. In D. M. Willows \& H. A. Houghton, Eds. The Psychology of Illustrations, Vol. 1, pp. 152-198. New York: Springer-Verlag.

Winn, W. (1989). The design and use of instructional graphics. In H. MandL \& J. R. Levin, Eds. Knowledge Acquisition from Text and Pictures, pp. 125-144. Amsterdam: North Holland.

Wood, D. (1992). The Power of Maps. NY: Guilford.

Woodward, D. \& Lewis, G. M. (1994). The History of Cartography: Cartography in the Traditional East and Southeast Asian Societies, Vol. 2, Book 2. Chicago: University of Chicago Press.

Yates, F. A. (1969). The Art of Memory. New York: Penguin.

Zacks, J., Levy, E., Tversky, B. \& Schiano, D. J. (1998). Reading bar graphs: effects of depth cues and graphical context. Journal of Experimental Psychology: Applied, 4, 119-138.

Zacks, J., Tversky, B. \& IYer, G. (2001). Perceiving, remembering, and communicating structure in events. Journal of Experimental Psychology: General, 130, 29-58. 